\title{
Una experiencia de trabajo teatral en el CERESO No. 1
}

\author{
Cutberto López Reyes*
}

Hace algunos años, producto de una visita ocasional al Centro de Readaptación Social No. 1 (CERESO), mejor conocido como "La Peni", terminé involucrado en lo que ha sido una de las aventuras más emocionantes en mi vida como gente de teatro.

Fueron cerca de ocho meses los que estuve trabajando en el montaje de una obra de teatro con un grupo de diez reclusos, entre hombres y mujeres.

No fue mi primera experiencia, a lo largo de mi vida he visitado en forma ocasional las cárceles.

¿Por qué hacer teatro en una cárcel?

¿Tiene sentido ensayar por meses una obra de teatro en condiciones no convencionales?

¿Cuál es el papel de una expresión artística entre personas que viven una situación de vulnerabilidad?

Los presos/actores manifestaron durante el montaje que en las horas de ensayo se sentían libres. No lo decían en forma metafórica, lo decían como algo real. Y es que el arte, la creación artística, te da la oportunidad de vivir emociones muy propias del arte mismo. Los reclusos le pusieron a ese conjunto de emociones el nombre de libertad.

Estar en la cárcel debe de ser terriblemente duro, aunque hay personas en la vida cotidiana que de seguro viven condiciones aún más difíciles. La pobreza es una cárcel. Para soportar la vida en prisión algunos internos aprovechan cualquier actividad fuera de lo ordinario para que el tiempo supuestamente pase más rápido. Hacer teatro es una buena oportunidad para que eso suceda y más si en el grupo van a participar hombres y mujeres.

\footnotetext{
* Dramaturgo y director teatral. Promotor cultural de la Universidad de Sonora. Forma parte del Sistema Nacional de Creadores del Fondo Nacional para la Cultura y las Artes.
}

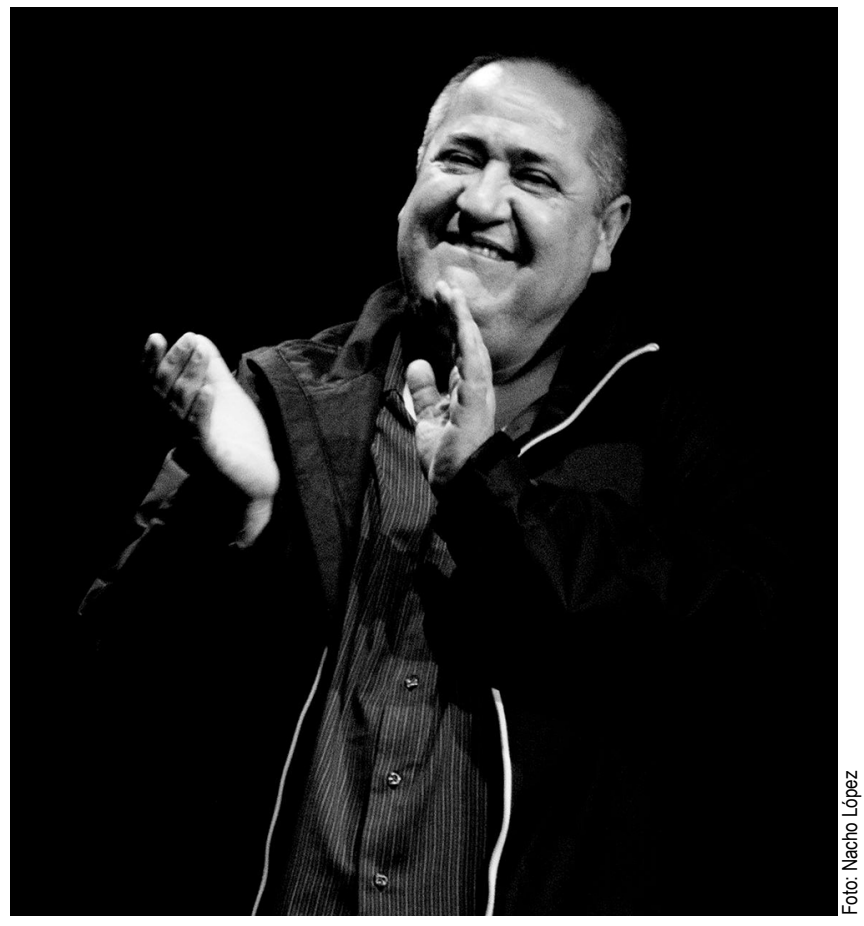

En mi experiencia, que fue intensa y profesional, me percaté de muchas cosas: el teatro es una herramienta poderosa para reconocerse a uno mismo. En el proceso, los presos reflexionaron sobre las circunstancias que los llevaron a la cárcel.

Por su naturaleza, el teatro se acerca un poco a la psicología. No llegamos a la profundidad del psicodrama, pero sí exploramos sobre asuntos muy puntuales en la vida de los internos: sobre sus relaciones emocionales en distintos planos, sobre su presunción de inocencia, sobre sus delitos y sobre sus procesos legales. 
El carácter colectivo del teatro posibilitó que en cada ensayo se dialogara sobre la vida en la cárcel misma, sobre la vida de afuera, sobre la familia y sobre el tiempo. El maldito tiempo que en la cárcel tiene distintas velocidades.

El rigor con el que realizamos el montaje fue tan o más intenso que cualquier montaje profesional. Cuando se va a trabajar con personas en situación de vulnerabilidad debemos dejar de lado la lástima o compasión. Un trato de iguales es fundamental para no crear barreras y evitar caer en chantajes emocionales.

Montamos un espectáculo de ocho monólogos titulado El diván, escrito por autores mexicanos y franceses. En todos los monólogos, el personaje, se supone que está en un diván, una especie de sillón, hablando con un psiquiatra de su desorden emocional. Cada actor escogió, con mi ayuda, su monólogo. Uno de los actores, que también es escritor, escribió su propio texto.

Durante el montaje me fui dando cuenta de que los internos aprovechaban el texto para contarnos su vida. Unos en forma muy cercana y otros un poco alejados. Recuerdo el caso de la chica que le quitó la vida a su hijo recién nacido y que actuó a una mujer que acudía al psiquiatra por sus recurrentes pesadillas en donde le arrancaban a su hijo de las manos y se perdía en un laberinto.

Otro chico interpretaba a un loco que mataba en la línea fronteriza a gringos que cruzaban a territorio mexicano para buscar mejores condiciones de vida. Este chico estuvo preso porque mató a un amigo que le debía un casette. En la vida cotidiana tenía problemas mentales y a veces dejaba de ir a ensayos porque, me lo confesó alguna vez, andaba muy loco y capaz que mataba a alguien.

Tuvimos una sola función del espectáculo. En esa función, la de estreno, invitamos a directivos del sistema penitenciario, artistas, maestros universitarios y otros perfiles. Quisimos mostrar a los de afuera el resultado de meses de trabajo de los de adentro. Fue una función memorable. El público estaba sorprendido y admirado por los alcances artísticos de los reclusos. El mismo día del estreno, una de las actrices fue trasladada a las Islas Marías y se sucedieron una serie de acontecimientos que impidieron hacer funciones para los otros internos. El proyecto quedó trunco.

De los actores, seis están en libertad, uno murió en la cárcel y una permanece recluida. A veces me he topado con algunos de ellos en la calle y emocionados nos saludamos. Quizás son ellos los que deben de hablar sobre lo que vivieron en el montaje de la obra de teatro.

Hace ya cerca de treinta años, y en esta misma aula, la que es ahora mi esposa, daba clases a alumnos de trabajo social de teatro y periodismo popular. Yo le ayudaba con las clases de teatro. Les compartíamos a los alumnos las herramientas para que pudieran montar sociodramas en sus prácticas comunitarias. El sociodrama es una forma del teatro en donde se aborda de manera muy directa alguna problemática social.

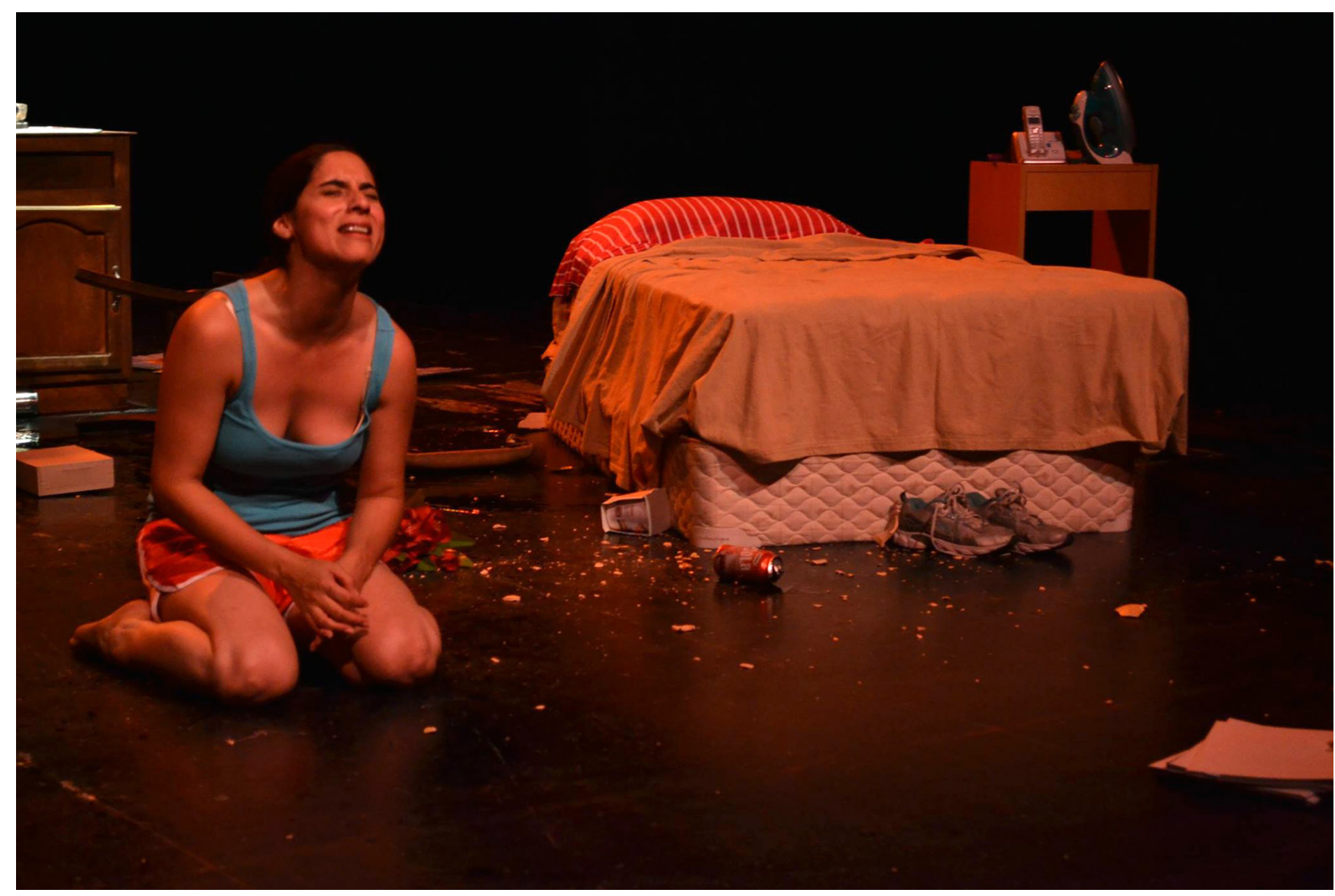


Me parece que el trabajador social debe de ser un profesional capaz de imaginar y crear mecanismos no tradicionales para contribuir a resolver las situaciones que ha detectado como problemas en la comunidad donde trabaja.

El taller, la conferencia, la charla, la intervención, las jornadas y otros mecanismos que según yo, se utilizan, pueden ser fortalecidos con la organización de una experiencia creativa y artística.

El arte posibilita la reflexión, pero en forma divertida, permite por la vía sensible, abordar nuestra compleja naturaleza humana.

No es necesario que el trabajador social sea un artista. Lo que es fundamental es que sea un facilitador, un organizador, un enlace entre los artistas y las comunidades.

El artista es un ser sensible y si bien es cierto, lucha por su profesionalización; también entiende que tiene una responsabilidad social y que la solidaridad entre los ciudadanos es una actitud inherente a su propia condición de artista.

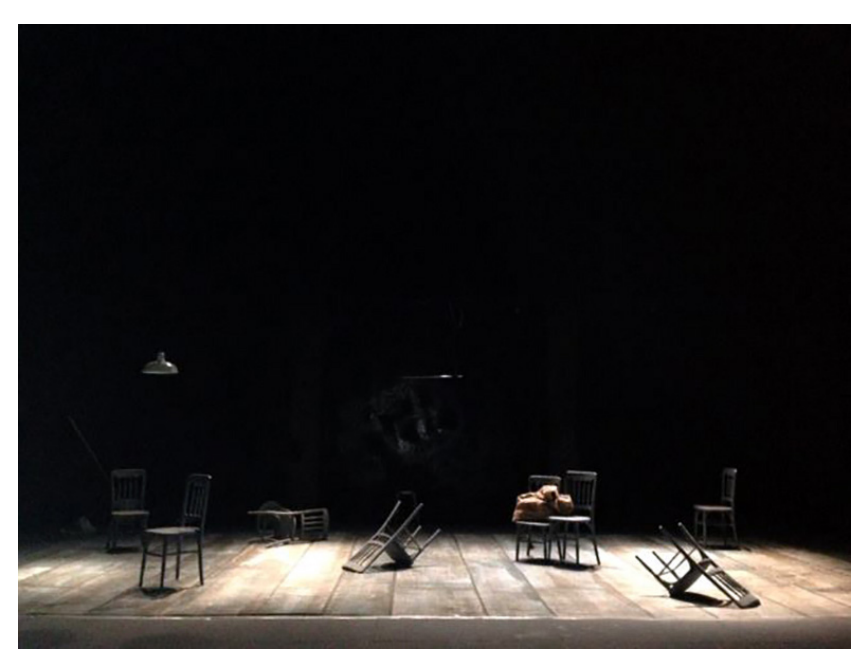

En México se ha desarrollado en los últimos quince años un campo de estudio y trabajo en la gestión cultural. Existen muchas formas de hacer gestión cultural en las comunidades. Puede resultar difícil porque no se considera prioritario invertir recursos en este tema. Una forma que puede garantizar el impulso de estos programas es establecer alianzas con los especialistas en el tema.

El trabajo cultural tiene una dinámica muy específica. A simple vista puede resultar sencillo, pero si no hay una metodología adecuada puede llegar a convertirse solo en una actividad más.

Vivimos en un mundo complejo y con tantas necesidades y pobreza, que uno puede llegar a la frustración en su intento de mejorar las condiciones de vida de nuestras comunidades.
Por su naturaleza, el trabajo artístico no ofrece a simple vista resultados tangibles e inmediatos. Como en su esencia, el arte es una profunda reflexión sobre el ser humano, su impacto es casi intangible, no lo podemos medir en forma inmediata.

Pero no por eso debe dejar de impulsarse programas de arte en las comunidades. Uno nunca sabe a ciencia cierta lo que está sembrando, pero es seguro que al final se cosechará un pequeño cambio. Esto puede suceder años después porque la experiencia sensible del arte no tiene efectos inmediatos. Bueno, no siempre.

Y para concluir, debo expresarles que la experiencia de mi trabajo en la cárcel, marcó mi vida. Más allá del impacto en la vida de los demás, está el impacto en mi vida. Aprendí muchas cosas de la naturaleza humana. Vi de cerca el rostro de la pobreza y la marginación. He escrito algunos textos a partir de eso.

Si ustedes, como trabajadores sociales, incursionan en el trabajo artístico y cultural comunitario, van a transformar sus vidas. Van a desarrollar una sensibilidad que les será de gran ayuda en su vida privada y laboral.

A fin de cuentas, el arte busca en el fondo que seamos mejores seres humanos. 